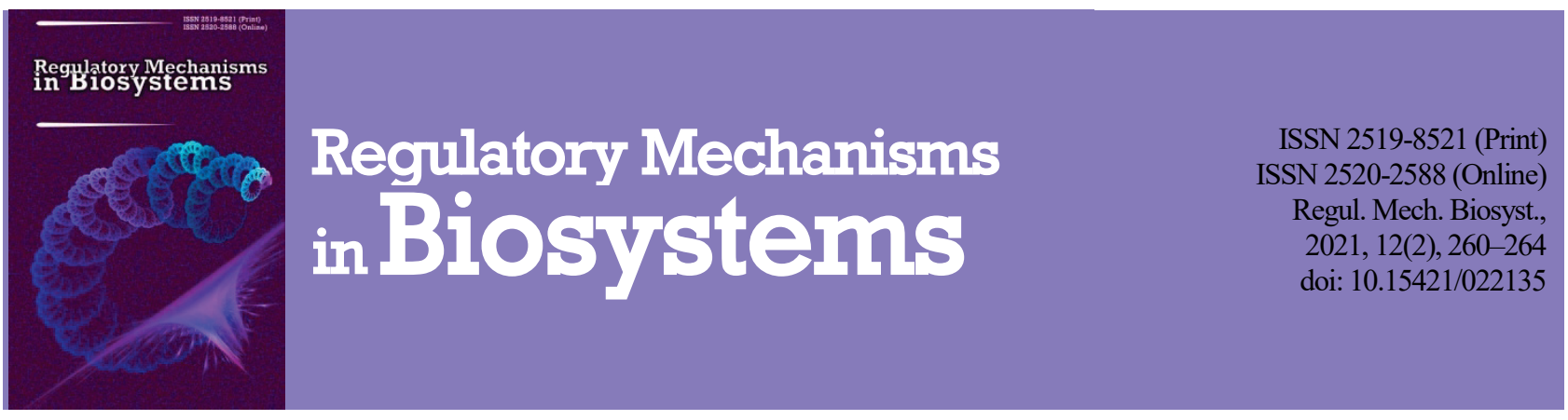

\title{
Altering maize (Zea mays) seedlings' growth and lignification processes by action of novel synthesized compounds
}

\author{
Y. V. Lykholat*, N. O. Khromykh*, O. O. Didur*, O. O. Gaponov*, M. M. Nazarenko**, T. Y. Lykholat* \\ *Oles Honchar Dnipro National University, Dnipro, Ukraine \\ **Dnipro State Agrarian and Economic University, Dnipro, Ukraine
}

Article info

Received 21.04.2021

Received in revised form 26.05.2021

Accepted 27.05.2021

Oles Honchar Dnipro National University

Gagarin av., 72

Dnipro, Ukraine, 49010

Tel.: $+38-050-487-87-17$

E-mail:khromykhn@ukr.net

Dnipro State Agrarian

and Economic University

Serhii Efremov st., 25 ,

Dnipro, 49600, Ukraine

Tel.: +38-095-848-53-86.

E-mail:

niknazarenko@ukr.net
Lykholat, Y. V., Khromykh, N. O., Didur, O. O., Gaponov, O. O., Nazarenko, M. M., \& Lykholat, T. Y. (2021). Altering maize (Zea mays) seedlings' growth and lignification processes by action of novel synthesized compounds. Regulatory Mechanisms in Biosystems, 12(2), 260-264. doi:10.15421/022135

Effective management of the course of crop vegetation and adaptation to biotic and abiotic stresses is a prerequisite for stable grain production and requires replenishment of the arsenal of plant growth regulators. The effect of novel synthesized cage amides on maize seedlings morphogenesis has been tested. Seeds of a mid-early maize hybrid 'DN Galatea' after the pre-sowing treatment with $0.01 \%$ solutions of test compounds were grown in distilled water. The roots and shoots sections of 10-day-old maize seedlings were stained with phloroglucinol solution to reveal the lignin-containing anatomical structures. The effects of nine different test compounds, exceeding the well-known effects of the phytohormone auxin, promoted the maize seedlings' linear growth, increased wet weight of roots and shoots, and dry biomass accumulation both in seedlings roots and shoots. Several test compounds activated the dry weight accumulation process without significantly affecting the root and shoot length. In the maize seedlings' roots, an increase in the diameter and number of the xylem vessels was found, as well as an increase in the lignin-containing layer thickness of the endoderm cells in the root cortex. In the maize seedlings' shoots, the test compounds caused an increase in the thickness of the lignin-containing outer layer of the seedlings' first leaf. In general, the test compounds' effect on seedling roots can potentially enhance root formation; increase efficiency of the roots waterconducting system and the tissues' strength, thus reducing the likelihood of root lodging in maize plants. The effects of the test compounds revealed in the seedlings' shoots reflect the activation of the shoots' structure formation and may have a positive value for enhancing the strength of the plant stems and counteracting the stem lodging of the maize plants.

Keywords: maize; seedlings; growth regulators; morphogenesis; lignin; endoderm; xylem.

\section{Introduction}

Increasing crop yield in parallel with enhancing plant resistance to biotic and abiotic stresses is a complex challenge, overcoming which depends on the ability to control the ontogenesis and adaptation of cultivated plants (Wang et al., 2018; Zhou et al., 2020; Divte et al., 2021). The use of products containing natural phytohormones remains an effective way of plant growth management including control of the fruit drop and improvement of fruit quality (Kumari et al., 2018); phytohormone derivatives can also be effective, as with cytokinin derivatives which stimulated the tillering and grain yield in spring barley and winter wheat (Koprna et al., 2021). However, the action of well-known plant growth regulators does not always provide the necessary effects and may not meet expectations in changing environmental conditions. Thus, according to recent research data of Pallaoro et al. (2016), the priming of corn seeds with addition of gibberellic acid does not provide increase in yield quality. Fawcett et al. (2016) found that the effect of gibberellic acid and cytokinins on maize and soybeans in field trials led to enhancement of plant growth only, while none of the treatments resulted in increased crop yields. The insufficient potential of jasmonic acid to improve the root system of rice seedlings exposed to pollutants has been identified (Lin et al., 2021). At the same time, novel synthesized compounds can expand the spectrum of beneficial biological effects and provide the desired changes at various stages of plant development and harvest. Stimulation of the root formation process in stem cuttings of blackberry plants was much more effective under the action of synthesized triazole derivatives as compared to the known phytohormonal plant growth regulator (Shcherbina et al., 2017). A comparative study of response of Lilium plants to action of natural and synthesized regulators showed a significantly smaller effect of gibberellic acid on the height, leaf number and leaf area than the effect of paclobutrazol on plant morphology and anatomy (Torres-Pio et al., 2021).

Ample opportunities to control plant growth can be provided by influencing the level of endogenous plant hormones, including gibberellins, abscisic acid, and cytokinins, as found by Desta \& Amare (2021) when investigating the growth-regulating properties of paclobutrazol, which belongs to the triazole family. It turned out that paclobutrazol affects isoprene biosynthesis and changes the levels of plant hormones, inhibiting the synthesis of gibberellin and increasing the cytokinins' level, thus reducing the stem elongation. The effect of growth regulators paclobutrazol and uniconazole on turf grass Zoysia japonica under water deficit was manifested in a decrease in the transpiration rate, plant vertical growth and biomass accumulation while increasing the chlorophyll content in tissues and abscisic acid concentration in the leaves (Cohen et al., 2019).

The use of novel synthesized growth regulators provides effective means to reduce the lodging of cereals stems and roots, which is still a serious problem, leads to crop losses and complicates the harvesting process (Emdwein et al., 2020; Tirado et al., 2021). For example, the treatment of rice crops with growth regulator trinexapac-ethyl caused a decrease in plant height and the lodging degree, and a larger crop yield as a result (Corbin et al., 2016). Similarly, in the soft white winter wheat crops, growth-regulating compounds chlormequat chloride-CC and trinexapacethyl-TE eliminated crop lodging and yield losses, reducing linear plant growth (Qin et al., 2020). According to recent research, a decrease in grain crops stem lodging is due to the appearance of a greater strength of the 
plants' structural parts and correlates with change in chemical composition of the cell walls, including the lignin content (Begović et al., 2018; Heuschele et al., 2020; Huang et al., 2021). We have previously reported the positive effects of several synthesized 3-sulfolene derivatives on the growth and development of maize seedlings, including an increase in the vigour index, root and shoot length (Palchikov et al., 2019). The aim of this work was to identify the features of morphogenesis and lignification of cell walls of the roots and shoots of maize seedlings, caused by treatment of the seeds with the novel synthesized cage amides.

\section{Materials and methods}

The research object was maize (Zea mays L.) seedlings of the 'DN Galatea' hybrid created in Ukraine. Seeds were immersed for $6 \mathrm{~h}$ with $0.01 \%$ aqueous solutions of the test compounds at the temperature of $24^{\circ} \mathrm{C}$. The well-known phytohormone auxin in the same concentration was used as standard growth regulator. Control maize seeds were soaked in distilled water. Then, all seeds were washed with distilled water, wrapped in filter paper tubes and grown in distilled water in a thermostat at a temperature of $22.0 \pm 0.2{ }^{\circ} \mathrm{C}$ in the dark for 6 days; after that, the seedlings grew for the next 4 days, being 8 hours in room lighting and 16 hours in the dark. The first stage of the experiment concerned the effect of the synthesized test compounds on seed germination and seedlings' morphometric parameters. The length and wet weight of roots and shoots were measured on the 10th day, the dry weight was determined after drying for 12 hours at a temperature of $60^{\circ} \mathrm{C}$. The new synthesized cage amides, which caused a decrease in the corn seeds' native germination, were not included in further studies. In the current study, 9 compounds, the synthesis of which was previously described (Pal'chikov et al., 2018), were evaluated for the effects on the corn seedlings' morphological and anatomical traits (Table 1).

To reveal the histological effects of the test compounds, sections of the roots and shoots conductive zone of 10-day-old maize seedlings were moistened with a freshly prepared $0.5 \%$ phloroglucinol solution, which stains lignin-containing plant tissues in a red-crimson colour (Barykina et al., 2000). Microphotography of transverse histological sections of the maize seedlings' roots and stems was carried out at $4 \mathrm{x}$ and $10 \mathrm{x}$ magnification using an Ulab XY-B2T LED microscope equipped with a trinocular attachment for connecting a digital camera-eyepiece. A minimum of 10 visual fields were processed in each histological section. For morphometric measurements of anatomical structures, computer programs for image analysis TSView version 7.1.1.5 Copyright by Tucsen Imaging Technology Co., Limited were used.

Analyzed parameters, including the thickness of the endoderm cells of the maize seedling root primary cortex $(\mu \mathrm{m})$, the diameter of the xylem vessels of the conductive bundle of the seedling roots central cylinder $(\mu \mathrm{m})$, as well as the thickness of the outer layer of the coiled first leaf of seedling $(\mu \mathrm{m})$, were processed using variance method (ANOVA) factorial experiment, and the differences between means were tested with Tukey's HSD. All differences were considered to be statistically significant at $\mathrm{P}<0.05$.

\section{Results}

New synthesized cage amides that did not reduce seed germination and were selected for further studies had different effects on the morphometric parameters of the maize seedlings compared both to control plants and effects of well-known plant growth regulator auxin action (Table 2).

The greatest increase in the maize seedlings' root length, exceeding the control and the auxin effect, was caused by the action of test compound $\mathrm{V}$, and the maximum elongation of the shoots was caused by the action of compound VII. The effects of test compounds on the maize seedlings' wet weight did not correlate with changes in dry weight. Test compounds IV, I, and II caused the greatest increase in the wet weight of seedling roots $(23.2 \%, 20.1 \%$ and $18.8 \%$ above the control), whereas the dry weight of the roots was increased the most by test compounds IV, VII, and I (19.8\%, 21.4\% and 19.0\% above the control). The wet weight of the maize seedlings' shoots increased most of all under the influence of the test compounds IV, II and VI (within 10\% of the control); the greatest increase in shoots' dry weight was caused by the action of the test compounds VI, III and VII (20.1\%, $17.1 \%$ and $14.1 \%$ above the control).

Table 1

Chemical structure of new synthesized cage amides tested in the experiment

Condition code

(3aR,4R,5S,6S,7S,7aS)-5,6-dihydroxy-2-methylhexahydro1H-4,7-methanoisoindole-1,3(2H)-dione

Compound II<smiles>Cc1ccc(N2C(=O)C3C4C=CC(C4)C3C2=O)cc1</smiles>

(3a $R, 4 S, 7 R, 7 \mathrm{a} S)$-2-(p-tolyl)-3a,4,7,7a-tetrahydro-1 $H$ 4,7-methanoisoindole-1,3(2H)-dione

Compound III<smiles></smiles>

(3a R,4S,7R,7aS)-2-(1,5-dimethyl-3-oxo-2-phenyl-2,3dihydro-1H-pyrazol-4-yl)-3a,4,7,7a-tetrahydro-1H-4,7methanoisoindole-1,3(2H)-dione

Compound IV<smiles>O=C(Nc1ccccn1)C1C2C=CC(C2)C1O</smiles>

$(1 R, 2 S, 3 R, 4 S)$-3-(pyridin-2-ylcarbamoyl)bicyclo[2.2.1]-hept5-ene-2-carboxylic acid

Compound V<smiles>O=C(O)CN1C(=O)C2C3C=CC(C3)C2C1=O</smiles>

2-((3aR,4S,7R,7aS)-1,3-dioxo-1,3,3a,4,7,7a-hexahydro-2H4,7-methanoisoindol-2-yl)acetic acid

Compound VI<smiles>CN1C(=O)C2C3C=CC(C3)C2C1=O</smiles>

(3aR,4S,7R,7aS)-2-methyl-3a,4,7,7a-tetrahydro- $1 H$ 4,7-methanoisoindole-1,3(2H)-dione

Compound VII<smiles>O=S1(=O)C=C(NBr)CCC1</smiles>

5-(benzylamino)-3,4-dihydro-2H-thiopyran 1,1-dioxide<smiles>O=C1C(O)CC2CC1CN2Cc1ccccc1</smiles>

(1S,4R,6R)-2-benzyl-6-hydroxy-2-azabicyclo [2.2.2] octan-3one<smiles>CN(C)CCN(CCO)C(=O)C1C2C=CC(C2)C1O</smiles>

3-(4-ethylpiperazine-1-carbonyl) bicyclo[2.2.1]-hept-5-ene-2carboxylic acid 
Table 2

Test compounds effects on growth and development of maize seedlings of the hybrid 'DN Galatea' $(\mathrm{x} \pm \mathrm{SD}, \mathrm{n}=20, \mathrm{P}<0.05)$

\begin{tabular}{|c|c|c|c|c|c|c|}
\hline \multirow{2}{*}{ Compound } & \multicolumn{2}{|c|}{ Length, $\%$ of control } & \multicolumn{2}{|c|}{ Wet weight, $\%$ of control } & \multicolumn{2}{|c|}{ Dry weight \% \% of control } \\
\hline & roots & shoots & roots & shoots & roots & shoots \\
\hline$\overline{\text { Auxin }}$ & $111.0 \pm 1.7^{\mathrm{ac}}$ & $109.3 \pm 2.7^{\mathrm{a}}$ & $108.5 \pm 10.9^{\mathrm{a}}$ & $109.5 \pm 1.2^{\mathrm{a}}$ & $113.0 \pm 5.1^{\mathrm{a}}$ & $116.0 \pm 6.1^{\mathrm{a}}$ \\
\hline Compound I & $105.1 \pm 4.0^{\mathrm{ac}}$ & $114.3 \pm 2.1^{\mathrm{a}}$ & $123.9 \pm 4.3^{\mathrm{ab}}$ & $105.9 \pm 6.3^{\mathrm{a}}$ & $119.0 \pm 17.8^{\mathrm{a}}$ & $112.7 \pm 15.3^{\mathrm{a}}$ \\
\hline Compound II & $106.6 \pm 4.2^{\mathrm{ac}}$ & $102.6 \pm 3.8^{\mathrm{abc}}$ & $115.5 \pm 2.7^{\mathrm{a}}$ & $105.4 \pm 7.7^{\mathrm{a}}$ & $110.9 \pm 9.5^{\mathrm{a}}$ & $111.9 \pm 8.9^{\mathrm{a}}$ \\
\hline Compound IIII & $104.3 \pm 3.1^{\mathrm{ac}}$ & $106.1 \pm 1.2^{\mathrm{ab}}$ & $98.0 \pm 2.0^{\mathrm{ac}}$ & $105.7 \pm 2.9^{\mathrm{a}}$ & $108.4 \pm 3.9^{\mathrm{a}}$ & $117.1 \pm 4.0^{\mathrm{a}}$ \\
\hline Compound IV & $103.5 \pm 2.1^{\mathrm{ac}}$ & $97.8 \pm 1.3^{\mathrm{b}}$ & $123.2 \pm 4.1^{\mathrm{a}}$ & $110.3 \pm 3.1^{\mathrm{a}}$ & $119.8 \pm 4.9^{\mathrm{a}}$ & $106.2 \pm 3.4^{\mathrm{a}}$ \\
\hline Compound V & $112.0 \pm 1.7^{\mathrm{ac}}$ & $108.9 \pm 5.1^{\mathrm{a}}$ & $111.3 \pm 2.5^{\mathrm{a}}$ & $105.4 \pm 4.0^{\mathrm{a}}$ & $108.4 \pm 7.4^{\mathrm{a}}$ & $107.0 \pm 3.8^{\mathrm{a}}$ \\
\hline Compound VI & $105.9 \pm 4.7^{\mathrm{ac}}$ & $109.4 \pm 6.1^{\mathrm{a}}$ & $111.4 \pm 11.2^{\mathrm{a}}$ & $108.2 \pm 11.8^{\mathrm{a}}$ & $113.7 \pm 6.1^{\mathrm{a}}$ & $120.1 \pm 5.1^{\mathrm{a}}$ \\
\hline Compound VII & $110.5 \pm 3.5^{\mathrm{ac}}$ & $110.6 \pm 4.3^{\mathrm{a}}$ & $113.2 \pm 21.2^{\mathrm{a}}$ & $103.3 \pm 7.7^{\mathrm{a}}$ & $121.4 \pm 4.7^{\mathrm{a}}$ & $114.1 \pm 6.7^{\mathrm{a}}$ \\
\hline Compound VIII & $98.5 \pm 0.6^{b}$ & $97.6 \pm 3.1^{\mathrm{bc}}$ & $107.6 \pm 5.3^{\mathrm{a}}$ & $99.7 \pm 2.5^{\mathrm{a}}$ & $114.9 \pm 12.4^{\mathrm{a}}$ & $113.8 \pm 4.2^{\mathrm{a}}$ \\
\hline Compound IX & $102.6 \pm 2.1^{\mathrm{ad}}$ & $94.8 \pm 1.8^{\text {bod }}$ & $110.2 \pm 1.7^{\mathrm{a}}$ & $102.2 \pm 2.4^{\mathrm{a}}$ & $117.5 \pm 6.6^{\mathrm{a}}$ & $107.8 \pm 1.5^{\mathrm{a}}$ \\
\hline
\end{tabular}

Note: the different letters indicate statistically significant differences in the means of the compared pair according to the Tukey criterion (HSD); all test compounds were taken in $0.01 \%$ concentration.

Compared to auxin, seven test compounds had a greater effect on the wet weight of the maize seedling roots, however, only compound IV caused a greater increase in wet weight of the shoots; six test compounds caused a greater increase in the dry weight of seedling roots and five test compounds caused a greater increase in shoots dry weight.

The study of stained sections of the maize seedlings roots by microscopy showed different effects of the test compounds on some anatomical structures. Measurement of root endoderm cell thickness revealed an excess of this indicator under the influence of test compounds in comparison with the control and the effect of auxin (Fig. 1).

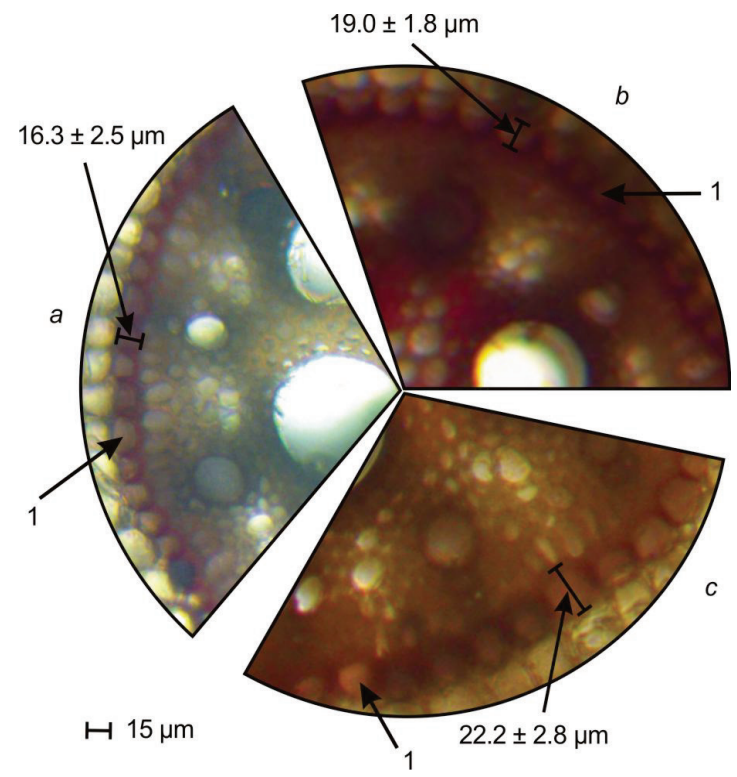

Fig. 1. Effect of the test compounds on the endoderm cells thickness in the primary cortex of maize seedlings roots: $a$-control, $b$-auxin, $c$-compound IX, 1 - endoderm

The effect of all test compounds on the thickness of endoderm cells layer in the maize seedlings roots was positive, and the degree of changes varied within $10.8-37.6 \%$ in relation to the control (Table 3 ).

The diameter of the xylem vessels in the conductive bundle of the central cylinder of the roots of maize seedlings increased under the influence of some test compounds, exceeding not only the control value, but also the auxin effect (Fig. 2).

The level of a significant positive effect of the test compounds on the xylem vessels' diameter varied in the range of $5.2-24.8 \%$ relative to the control. The level of significant negative effect varied from $16.2 \%$ to $50.1 \%$ depending on the synthesized compound properties (Table 4 ).

The influence of test compounds on the xylem development in the central cylinder of the maize seedlings' roots was revealed on the root sections as the change in the number of vessels (Table 5). A posteriori comparisons of the number of xylem vessels in the experimental groups with the control showed both negative and positive effects of the test compounds. Thus, compound VI caused a significant decrease in the number of xylem vessels, while a statistically significant increase in the number of vessels was observed under the action of other test compounds, especially VIII, IV, II, VII (Table 5).

Table 3

Test compounds' influence on the primary root cortex of maize seedlings $(\mathrm{x} \pm \mathrm{SD}, \mathrm{n}=25, \mathrm{P}<0.05)$

\begin{tabular}{lcc}
\hline \multicolumn{1}{c}{ Compound } & Endoderm cell thickness, $\mathrm{m} \mu$ & To control, \% \\
\hline Compound V & $16.6 \pm 1.7^{\mathrm{a}}$ & 101.7 \\
Compound VI & $17.0 \pm 2.0^{\mathrm{a}}$ & 104.3 \\
Compound I & $17.1 \pm 1.4^{\mathrm{a}}$ & 104.7 \\
Compound IV & $17.7 \pm 1.8^{\mathrm{a}}$ & 108.0 \\
Compound VII & $17.9 \pm 1.5^{\mathrm{a}}$ & 109.5 \\
Compound III & $18.1 \pm 2.2^{\mathrm{a}}$ & 110.8 \\
Auxin & $19.0 \pm 1.8^{\mathrm{b}}$ & 116.3 \\
Compound VIII & $20.6 \pm 2.0^{\mathrm{b}}$ & 126.3 \\
Compound IX & $22.2 \pm 2.8^{\mathrm{bc}}$ & 135.6 \\
Compound II & $22.5 \pm 2.3^{\mathrm{bc}}$ & 137.6 \\
\hline
\end{tabular}

Note: the different letters indicate statistically significant differences in the means of the compared pair according to the Tukey criterion (HSD); all test compounds were taken in $0.01 \%$ concentration

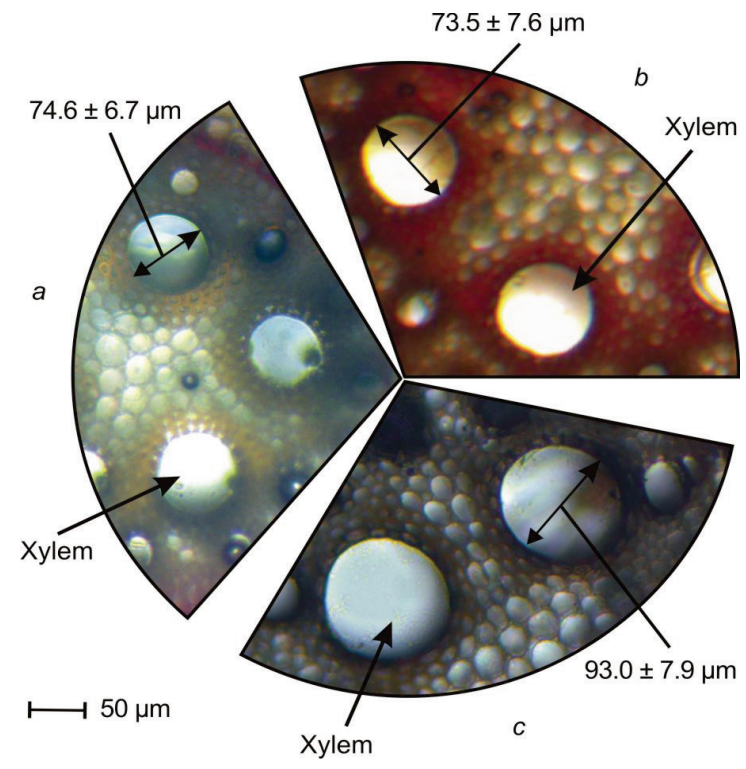

Fig. 2. Effect of the test compounds on the xylem cells diameter of the maize seedlings' roots: $a$-control, $b$-auxin, $c$ - compound VIII

In the sections of phloroglucinol-stained maize seedling shoots, microscopic examinations revealed multidirectional effects of the test compounds' action on the thickness of the tube-like first leaf of the maize seedlings (Fig. 3). The significant positive effect of the test compounds on the first leaf thickness varied in the range of $32.3-92.1 \%$ compared to the control. A negative effect on the thickness of the maize seedlings' first leaf was found in a smaller number of test compounds and was not significant (Table 6). 
Table 4

Effect of test compounds on the xylem

of maize seedlings' roots $(\mathrm{x} \pm \mathrm{SD}, \mathrm{n}=25, \mathrm{P}<0.05)$

\begin{tabular}{lcc}
\hline \multicolumn{1}{c}{ Compound } & Vessels diameter in root primary xylem, $\mu \mathrm{m}$ & To control, $\%$ \\
\hline Compound VI & $37.2 \pm 2.8^{\mathrm{a}}$ & 49.9 \\
Compound I & $62.4 \pm 4.5^{\mathrm{b}}$ & 83.8 \\
Compound IV & $68.9 \pm 7.5^{\mathrm{b}}$ & 92.4 \\
Compound II & $69.7 \pm 2.8^{\mathrm{bc}}$ & 93.5 \\
Auxin & $73.5 \pm 7.6^{\mathrm{c}}$ & 98.6 \\
Compound IX & $75.4 \pm 9.7^{\mathrm{bc}}$ & 101.2 \\
Compound V & $76.0 \pm 7.4^{\mathrm{c}}$ & 102.0 \\
Compound III & $78.4 \pm 7.0^{\mathrm{c}}$ & 105.2 \\
Compound VII & $81.5 \pm 8.6^{\mathrm{b}}$ & 109.4 \\
Compound VIII & $93.0 \pm 7.9^{\mathrm{bd}}$ & 124.8 \\
\hline
\end{tabular}

Note: the different letters indicate statistically significant differences in the means of the compared pair according to the Tukey criterion (HSD); all test compounds were taken in $0.01 \%$ concentration.

\section{Table 5}

Effect of test compounds on the number of xylem vessels in the roots of maize seedlings $(\mathrm{x} \pm \mathrm{SD}, \mathrm{n}=25, \mathrm{P}<0.05)$

\begin{tabular}{lcc}
\hline \multicolumn{1}{c}{ Compound } & Xylem vessels number, pcs & To control, \% \\
\hline Compound VI & $5.05 \pm 0.22^{\mathrm{a}}$ & 85.8 \\
Compound V & $5.88 \pm 0.34^{\mathrm{bcd}}$ & 99.9 \\
Compound IX & $6.45 \pm 0.53^{\mathrm{bc}}$ & 109.7 \\
Compound III & $6.60 \pm 0.51^{\mathrm{bc}}$ & 112.2 \\
Auxin & $6.69 \pm 0.48^{\mathrm{bc}}$ & 113.8 \\
Compound I & $6.69 \pm 0.48^{\mathrm{bc}}$ & 113.8 \\
Compound VIII & $6.82 \pm 0.40^{\mathrm{bec}}$ & 116.0 \\
Compound IV & $6.90 \pm 0.32^{\mathrm{bec}}$ & 117.3 \\
Compound II & $6.94 \pm 0.66^{\mathrm{be}}$ & 118.0 \\
Compound VII & $7.05 \pm 0.44^{\text {bee }}$ & 119.9 \\
\hline
\end{tabular}

Note: the different letters indicate statistically significant differences in the means of the compared pair according to the Tukey criterion (HSD); all test compounds were taken in $0.01 \%$ concentration.

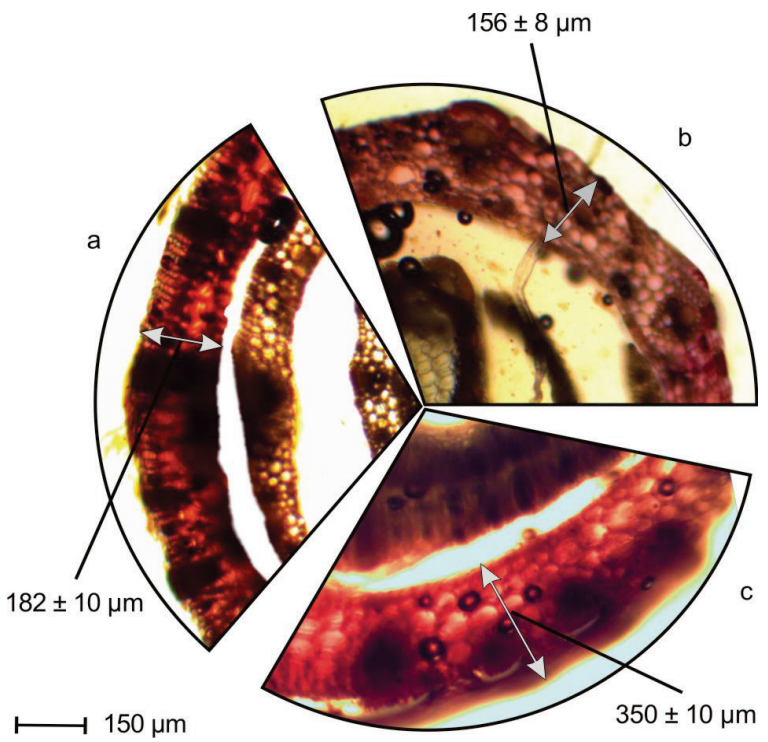

Fig. 3. Increase in the outer layer thickness of the first leaf of maize seedlings under the action of test compounds: $a$-control, $b$-auxin, $c$-compound VII

\section{Discussion}

The effects of the test compounds, exceeding the influence of auxin on the maize seedlings, were manifested in the enhancement of growth processes in the roots (compound V) and shoots (compound VII), an increase in the wet weight of the roots (compounds I, II, IV and VII) and shoots (compound IV) and dry biomass accumulation in roots (compounds I, II, IX, VII, VIII and IX) and shoots (compounds III, VI and VII) of seedlings. The promotion of seedling root formation with compound $\mathrm{V}$ can be beneficial as the root system of the maize plants is slow to develop both horizontally and deeply. At the same time, the rooting depth was one of the main factors in the maize root lodging occurrence, as modeling showed (Brune et al., 2018; Berry et al., 2021). Some test compounds caused the growth of seedlings' dry weight without significantly affecting the seedlings' roots and shoots' length. Namely, the root dry weight was affected by test compounds II, VIII, and IX, while test compounds III, VI and VII were successful in increasing shoot dry weight. The study of sections of maize seedlings' roots revealed an increase in the diameter of xylem vessels under the influence of test compounds III, VII, and VIII, as well as an increase in the number of vessels (test compounds II, IV, and VIII). The changes in the seedling roots' anatomical structure caused by the test compounds exceeded the auxin effect and can potentially enhance the efficiency of the vascular system of the maize plant's roots. A similar increase in vascular area and dry weight per unit length of the maize plants' internodes identified by Huang et al. (2021), when studying a new growth regulator, was assessed as a positive effect that increases the quality of internodes and reduces the stem lodging.

Table 6

Influence of test compounds on the thickness of maize seedling leaf $(\mathrm{x} \pm \mathrm{SD}, \mathrm{n}=25, \mathrm{P}<0.05)$

\begin{tabular}{lcc}
\hline \multicolumn{1}{c}{ Compound } & First leaf thickness, $\mu \mathrm{m}$ & To control, $\%$ \\
\hline Control & $182.4 \pm 9.7^{\mathrm{a}}$ & 100.0 \\
Auxin & $156.1 \pm 8.1^{\mathrm{a}}$ & 85.5 \\
Compound VI & $170.2 \pm 7.3^{\mathrm{a}}$ & 93.3 \\
Compound II & $171.0 \pm 8.4^{\mathrm{a}}$ & 93.8 \\
Compound IV & $176.0 \pm 9.7^{\mathrm{a}}$ & 96.5 \\
Compound I & $197.6 \pm 9.2^{\mathrm{a}}$ & 108.3 \\
Compound V & $200.2 \pm 13.1^{\mathrm{ac}}$ & 109.7 \\
Compound IX & $241.4 \pm 9.2^{\mathrm{b}}$ & 132.3 \\
Compound III & $246.9 \pm 8.4^{\mathrm{b}}$ & 135.3 \\
Compound VIII & $340.9 \pm 9.2^{\mathrm{b}}$ & 186.9 \\
Compound VII & $350.5 \pm 10.3^{\mathrm{b}}$ & 192.1 \\
\hline
\end{tabular}

Note: the same letters indicate statistically insignificant differences in the means of the compared pair according to the Tukey criterion (HSD); all test compounds were taken in $0.01 \%$ concentration.

According to the study results, the thickness of the phloroglucinolstained structures of the maize seedling roots increased under the influence of test compounds, indicating the activation of lignin accumulation in the cell walls of the root endodermal layer. The effect of test compounds II, VIII, and IX significantly exceeded the similar effect of auxin. Lignification of plant tissues is an important and not fully understood process that determines the structural and functional features of plants. For example, a comparative study of the physiological aspects of lignin synthesis in barley cultivars with different lodging phenotype showed that the internode lignification process is strongly influenced by genotype and environmental factors that determine the dynamics of lignin synthesis and its deposition in the cell walls (Begović et al., 2018). Lignin is a hydrophobic heterogeneous polymer composed of phenolic compounds, mainly of three hydroxycinnamyl alcohols (Kärkönen \& Koutaniemi, 2010). The lignin share in the plant dry mass in general is $20-25 \%$, the rest contains 40 $50 \%$ cellulose, $15-25 \%$ hemicelluloses, and $5-10 \%$ other components (Zeng et al., 2017). In plants, lignin accumulates in the cell walls of waterconducting tissues, making the cell walls hard, resilient, waterproof, and more resistant to pathogens. Lignin synthesis in plants can be induced in response to pathogenic invasion as a defense response (Polo et al., 2020). The important biological functions of lignin revealed to date include its contribution to plant growth, development of tissues and organs, resistance to lodging and to the action of various biotic and abiotic stresses (Liu et al., 2018). Thus, our established activation of the lignification process in the seedlings' roots with test compounds II, VIII, and IX may be a beneficial effect for maize plants. At the same time, test compounds I, IV, and VII, which also provided an increase in the dry weight of seedling roots, did not cause an enhanced lignin accumulation in the roots cell walls, which suggests the accumulation of other compounds not stained with phloroglucinol and not found on root sections.

In our work, the test compounds III, VII, VIII, and IX caused a thickening of the lignin-contained outer layer of the first rolled maize seedling leaf, in comparison with both the control and the auxin action. These effects may reflect the activation of the processes of shoot structure formation and have a positive value for enhancing the plant stem strength and 
counteracting the maize stem lodging. Research by Stubbs et al. (2020) showed that more active formation of rind tissues occurred in maize hybrids with a higher average bending strength of stems, in which the structural efficiency increases in resisting bending wind forces and the stem lodging decreases. Crop lodging resistance is a prerequisite for obtaining a consistently high yield and avoiding its losses during the harvesting process. In the recent studies, it has been established that a decrease in grain crop stem lodging is due to the appearance of a greater physical strength of the plant's structural parts and is associated with variations in the cell walls' chemical composition, including the lignin content (Heuschele et al., 2020). According to the results of the stalk lodging incidence study conducted on 47 maize hybrids, the lignin content in plant stems negatively correlated with the lodging frequency (Sekhon, 2020). During the growing season, maize plants can use lignin strategically, with smaller stems requiring more lignin while conversely less lignin is required for larger stems. However, a decrease in lignin content below the biologically optimal level, found in mutant plants, jeopardizes the cell wall strength, changes the plant morphology and leads to an increase in the stems' lodging frequency. Huang et al. (2021) showed an important role of the basal internode quality in enhancing the corn stalks' strength and reducing lodging, which is associated with changes in chemical composition, including an increase in cellulose and lignin content. In this regard, the ability of test compounds III and VI to induce the growth of roots and dry weight of shoots of the maize seedlings, without activating the seedlings' length growth, can potentially have a beneficial effect on improving the internode quality in mature maize plants.

\section{Conclusions}

The test compounds had both auxin-like and non-auxin effects on the morphological and anatomical characteristics of the roots and shoots of maize seedlings. In addition to elongation of roots and wet weight growth, an increase in the thickness of lignin-containing cells of the root cortex endodermal layer, an increase in the diameter and number of the xylem vessels in seedlings roots were revealed. The effects found can contribute to an increase in the efficiency of the root system formation of the maize seedlings, including the conducting system of the roots. The positive effect of the test compounds II, III, IV, VII, and VIII on the vascular area of the maize seedling roots was much higher than the effect of auxin. In the maize seedling shoots, the test compounds III, VII, VIII, and IX increased the thickness of the lignin-containing outer layer of the first leaf and increased the accumulation of dry biomass, which could potentially be useful in reducing stalk lodging in maize plants. The results obtained are quite significant confirmation that these new synthesized compounds can be recommended for the further testing as the components of plant growth regulators.

\section{References}

Barykina, R. P., Veselova, T. D., Deviatov, A. G., Dzhalilova, K. K., Ilina, G. M., \& Chubatova, N. V. (2000). Osnovy mikrotekhnicheskih issledovanij v botanike [Basics of microtechnical research in botany]. Moscow State University, Moscow (in Russian).

Begović, L., Abičić, I., Lalić, A., Lepeduš, H., Cesar, V., \& Leljak-Levanić, D. (2018). Lignin synthesis and accumulation in barley cultivars differing in their resistance to lodging. Plant Physiology and Biochemistry, 133, 142-148.

Berry, P. M., Baker, C. J., Hatley, D., Dong, R., Wang, X., Blackburn, G. A., Miao, Y., M. Sterling, \& Whyatt, J. D. (2021). Development and application of a model for calculating the risk of stem and root lodging in maize. Field Crops Research, 262(1), 108037.

Brune, P. F., Baumgarten, A., McKay, S. J., Technow, F., \& Podhiny, J. J. (2018). A biomechanical model for maize root lodging. Plant and Soil, 422, 397-408.

Cohen, I., Netzer, Y., Sthein, I., Gilichinsky, M., \& Tel-Or, E. (2019). Plant growth regulators improve drought tolerance, reduce growth and evapotranspiration in deficit irrigated Zoysia japonica under field conditions. Plant Growth Regulation, 88, 9-17.

Corbin, J. L., Walker, T. W., Orlowski, J. M., Krutz, L. J., Gore, J., Cox, M. S., \& Golden, B. R. (2016). Evaluation of trinexapac ethyl and nitrogen management to minimize lodging in rice. Agronomy Journal, 108(6), 2365-2370.
Desta, B., \& Amare, G. (2021). Paclobutrazol as a plant growth regulator. Chemical and Biological Technologies in Agriculture, 8(1), el-e15.

Divte, P. R., Yadav, P., Pawar, A. B., Sharma, V., Anand, A., Pandey, R., \& Singh, B. (2021). Crop response to iron deficiency is guided by cross-talk between phytohormones and their regulation of the root system architecture. Agricultural Research, in print.

Erndwein, L., Cook, D. D., Robertson, D. J., \& Sparks, E. E. (2020). Field-based mechanical phenotyping of cereal crops to assess lodging resistance. Applications in Plant Sciences, 8(8), e11382.

Fawcett, J., Koopman, Z., \& Miller, L. (2016). On-farm corn and soybean plant growth regulator trials. Farm Progress Reports, 2015(1), 152.

Heuschele, D. J., Smith, K. P., \& Annor, G. A. (2020). Variation in lignin, cell wallbound p-coumaric, and ferulic acid in the nodes and internodes of cereals and their impact on lodging. Journal of Agricultural and Food Chemistry, 68(45), 12569-12576.

Huang, G., Liu, Y., Guo, Y., Peng, C., Tan, W., Zhang, M., Li, Z., Zhou, Y., \& Duan, L. (2021). A novel plant growth regulator improves the grain yield of high-density maize crops by reducing stalk lodging and promoting a compact plant type. Field Crops Research, 260(1), 107982.

Kärkönen, A., \& Koutaniemi, S. (2010). Lignin biosynthesis studies in plant tissue cultures. Journal of Integrative Plant Biology, 52(2), 176-185.

Koprna, R., Humplík, J. F., Śpíšek, Z., Bryksová, M., Zatloukal, M., Mik, V., Novák, O., Nisler, J., \& Doležal, K. (2021). Improvement of tillering and grain yield by application of cytokinin derivatives in wheat and barley. Agronomy, 11, 67.

Kumari, S., Bakshi, P., Sharma, A., Wali, V. K., Jasrotia, A., \& Kour, S. (2018). Use of plant growth regulators for improving fruit production in sub-tropical crops. International Journal of Current Microbiology and Applied Sciences, $7(3), 659-668$.

Lin, Y. J., Feng, Y. X., Li, Y. H., Yu, G., \& Yu, X. Z. (2021). Fuzzy synthetic evaluation of the impact of plant growth regulators on the root phenotype traits of rice seedlings under thiocyanate stress. Plant Physiology and Biochemistry, 158, 182-189.

Liu, Q., Luo, L., \& Zheng, L. (2018). Lignins: Biosynthesis and biological functions in plants. International Journal of Molecular Sciences, 19, 335.

Pal'chikov, V. A., Gaponov, A. A., Chabanenko, R. M., \& Mykolenko, S. Y. (2018). Synthesis of a new spiro system: 1-oxa-7-thia-4-azaspiro[4.5]decane 7,7-dioxide. Russian Joumal of Organic Chemistry, 54(4), 588-592.

Palchykov, V., Khromykh, N., Lykholat, Y., Mykolenko, S., \& Lykholat, T. (2019). Synthesis and plant growth regulatory activity of 3-sulfolene derivatives. Chemistry and Chemical Technology, 13(4), $424-428$.

Pallaoro, D. S., Avelino, A. C., Camili, E. C., \& Guimaraes, S. (2016). Priming com seeds with plant growth regulator. Joumal of Seed Science, 38(3), 227-232.

Polo, C. C., Pereira, L., Mazzafera, P., Flores-Borges, D. N. A., Mayer, J. L. S., GuizarSicairos, M., Holler, M., Barsi-Andreeta, M., Westfahl Jr., H., \& Meneau, F. (2020). Correlations between lignin content and structural robustness in plants revealed by X-ray ptychography. Scientific Reports, 10, 6023.

Qin, R., Noulas, C., Wysocki, D., Liang, X., Wang, G., \& Lukas, S. (2020). Application of plant growth regulators on soft white winter wheat under different nitrogen fertilizer scenarios in irrigated fields. Agriculture, 10, 305.

Sekhon, R. S., Joyner, C. N., Ackerman, A. J., McMahan, C. S., Cook, D. D., \& Robertson, D. J. (2020). Stalk bending strength is strongly associated with maize stalk lodging incidence across multiple environments. Field Crops Research, 249(1), 107737.

Shcherbyna, R. O., Danilchenko, D. M., Parchenko, V. V., Panasenko, O. I., Knysh, E. H., Khromykh, N. O., \& Lykholat, Y. V. (2017). Studying of 2-((5-R-4-R14H-1,2,4-triazole-3-Yl)thio)acetic acid salts influence on growth and progress of blackberries (KIOWA Variety) propagules. Research Journal of Pharmaceutical, Biological and Chemical Science, 8, 975-979.

Stubbs, C. J., Seegmiller, K., McMahan, C., Sekhon, R. S., \& Robertson, D. J. (2020). Diverse maize hybrids are structurally inefficient at resisting wind induced bending forces that cause stalk lodging. Plant Methods, 16, 67.

Tirado, S. B., Hirsch, C. N., \& Springer, N. M. (2021). Utilizing temporal measurements from UAVs to assess root lodging in maize and its impact on productivity. Field Crops Research, 262, 108014.

Torres-Pio, K., Cruz-Guzmán, G. H., Arévalo-Galarza, M. L., Aguilar-Rodríguez, S., Grego-Valencia, D., Arriaga-Frías, A., \& Mandujano-Piña, M. (2021). Morphological and anatomical changes in Lilium cv. arcachon in response to plant growth regulators. Horticulture, Environment, and Biotechnology, 1-11.

Wang, J., Zhang, Z., \& Liu, Y. (2018). Spatial shifts in grain production increases in China and implications for food security. Land Use Policy, 74, 204-213.

Zeng, Y., Himmel, M. E., \& Ding, S. Y. (2017). Visualizing chemical functionality in plant cell walls. Biotechnol Biofuels, 10, 263.

Zhou, C., Zhang, R., Ning, X., \& Zheng, Z. (2020). Spatial-temporal characteristics in grain production and its influencing factors in the Huang-Huai-Hai Plain from 1995 to 2018. International Journal of Environmental Research and Public Health, 17(24), 9193. 